\title{
A Model and Test of Policymaking as Process
}

\author{
Catherine A Oakley ${ }^{1}$, George B Pesta ${ }^{2}$, Sabri Ciftci $^{3} \&$ Thomas G Blomberg ${ }^{1}$ \\ ${ }^{1}$ College of Criminology and Criminal Justice, Florida State University, United States \\ ${ }^{2}$ Center for Criminology and Public Policy Research, Florida State University, United States \\ ${ }^{3}$ Department of Political Science, Kansas State University, United States \\ Correspondence: Thomas G Blomberg, College of Criminology and Criminal Justice, Florida State University, \\ United States. E-mail: tgblomberg@aol.com
}

\author{
Received: September 20, 2013 Accepted: October 1, 2013 Online Published: November 29, 2013 \\ doi:10.5539/jpl.v6n4p1 URL: http://dx.doi.org/10.5539/jpl.v6n4p1
}

\begin{abstract}
The prior policymaking literature has been largely theoretical and focused upon agenda setting and the initiation mechanisms of policy change, namely triggering events. Notably absent from the prior literature have been studies aimed at developing and empirically evaluating models of policymaking as a process with outcomes. Such a process/outcome model of policymaking would necessarily include initiation mechanisms, or triggering events, agenda setting, politics, and subsequent outcomes (intended vs. unintended). This paper applies such a process and outcome model through an evaluative case study of the tragic death of Martin Lee Anderson in a Florida juvenile boot camp. The death of Martin Lee Anderson in January, 2006 sparked a major debate and a series of subsequent policy initiatives in Florida related to juvenile boot camps, the treatment of juveniles in confinement, and overall accountability of the state's juvenile justice system. Employing multiple data sources, the evaluation assesses the triggering events, subsequent processes, and resulting policy outcomes. The findings demonstrate that policymaking occurs in a sequential manner with identifiable stages. Different actors influence each stage of the process and help to shape the final policy outcomes. However, using the methods of in-depth interviews and participant observations revealed that outcomes are also shaped by various political negotiations which are not easily captured through conventional research and evaluation methods.
\end{abstract}

Keywords: policymaking, juvenile justice, policy evaluation, policymaking process

\section{Introduction}

In recent years increasing scholarly attention has been focused upon policymaking. While many scholars remain opposed or indifferent about the importance of policymaking to their academic pursuits, a growing number of scholars have embraced policymaking as a fundamental and integral part of their role as researchers. Emerging prominent from the growing interest in policymaking have been several theoretical accounts of what initiates policy development or change. Among these accounts are the Advocacy Coalition Framework (Sabatier \& Jenkins-Smith, 1993), Punctuated Equilibrium (Baumgartner \& Jones, 1993), and Kingdon's (2003) often cited contribution of "policy windows". Kingdon (2003) contends that there are particular events that precipitate opportunities to change or develop policy (pp. 166-167). Several other authors have extended or refined the policy windows argument in their respective efforts to advance theoretical understanding of policy agenda setting (Burstein, 1991; Birkland, 1997, 2004).

Most of the various theoretical accounts of policymaking have been focused upon identifying what initiates policymaking or change. Kingdon (2003) places emphasis upon social crises or unpredictable events, Downs (1972) identifies five stages of the "issue attention cycle", and Peters and Hogwood (1985) focus upon political/public attention and associated organizational activity. These different accounts have each identified the initiation, agenda setting, and/or policy opportunities and have demonstrated the important relationship between the initiation of policymaking and the larger context of society. Stated differently, these various theoretical accounts have revealed that policymaking and related initiatives are not timeless, nor do they emerge from a social vacuum. Rather, policymaking efforts are responsive to and shaped by various social, political, and economic events in which they take place and to which they are relevant. Nonetheless, these important theoretical contributions concerning the different factors involved in precipitating and shaping the policymaking agenda, the literature remains conceptually and empirically incomplete. Specifically, John (2003) has concluded that future 
policymaking theory and research will need to move beyond policy windows and agenda setting and toward the identification of the proximate causal mechanisms that subsequently drive policy change.

The prior policymaking literature has yet to conceptualize or empirically examine the actual policymaking process as it relates to the capacity for intended and unintended outcomes. To do so, any proposed model of the policymaking process must extend beyond the initiation stages of policymaking and link the subsequent policy stages in a sequential manner that includes potential political processes and outcomes. Questions that need to be addressed include: What occurs in policymaking following agenda setting? Why do some policymaking efforts result in their intended policy outcomes while others do not? Further, why do some policymaking efforts lead to unintended outcomes or outcomes contrary to what was intended in the original policymaking agenda? Clearly, extending policymaking theory and research to include agenda setting, process, implementation and subsequent outcomes is fundamental to advancing our understanding of policymaking.

This paper responds to the need to extend the study of policymaking into the areas of process and outcomes. The paper is centered upon Florida's policymaking response to the death of Martin Lee Anderson in a juvenile boot camp in 2006. This tragic event and subsequent reactions opened a policy window for sweeping reform of Florida's juvenile justice policy regarding boot camps, the treatment of youth in state custody, and the accountability of the state's juvenile justice system outcomes. During the policy window, several groups of actors participated in public debates that were fueled by the media, civil demonstrations and legislative hearings. As the policy problem was formulated and policy solutions were placed on the agenda, legislators began drafting bills in an effort to reach consensus. Ultimately, the Florida legislature passed the "Martin Lee Anderson Act" that resulted in what can be described as a moderate change in juvenile justice policy.

This paper includes a brief overview of the relevant literature, a proposed sequential model of policymaking, and presentation of the case study's evaluation findings. The paper concludes with a summary discussion of conceptual and empirical implications posed by the study's findings.

\section{Overview of Prior Research}

Since the more than a half century old contribution of Lasswell (1951), the policymaking literature has been focused upon discreet initiation stages and triggering events that precipitate policymaking. Notably absent from the prior descriptive and theoretical literature have been empirical studies capable of testing, refining and advancing our understanding of policymaking.

Following Lasswell's stages heuristic model, several scholars have described policymaking as involving a series of individual stages that are not necessarily interrelated, including problem identification, agenda setting, policy formulation, decisionmaking, and policy implementation (for an early account of stages heuristic see Jones (1984)) Several theoretical models were proposed in an effort to move beyond mere descriptive stages and to explain policymaking and policy change. Among those theoretical accounts are the Advocacy Coalition Framework (ACF) (Sabatier \& Jenkins-Smith, 1988, 1993; Jenkins-Smith \& Sabatier, 1994) which views policymaking within a policy domain that is comprised of key actors who share core beliefs and values and attempt to influence policy by forming coalitions; Punctuated Equilibrium model (Baumgartner \& Jones, 2002) in contrast defines policymaking as a process characterized by long periods of status quo, followed by abrupt changes and new stability (i.e., equilibrium) conditions. Both theories emphasize the initiation phases of the policy process and do not address the post-initiation and post-decision stages.

Only a few prior studies have conceptualized policymaking as a sequential and interrelated process. In his 1972 essay, Up and Down With Ecology: The "Issue-Attention Cycle", Anthony Downs described five stages of the policy process which are linked in a sequential manner (pp. 38-40). However, Downs' approach lacks a comprehensive picture of the policy process because it centers policymaking on agenda setting and public attention. Although empirical tests have confirmed the existence of an issue attention cycle (Peters \& Hogwood, 1985: p. 251), this approach does not address the inner workings of the policy process, including the black box of politics, competing solutions, implementation impediments, and the realization of intended and unintended outcomes.

Prominent in the policymaking research is the often cited work of Kingdon whose conceptualization of policymaking includes a multiple stages approach and evolutionary theory. According to Kingdon a problem is brought to public attention via a triggering event or routine situation and a policy window opens providing an opportunity for policy change to occur (2003, pp. 94-96, 116-167). Kingdon compares the policymaking process to biological evolutionary theory employing the metaphor of "primeval soup" where ideas and solutions are generated by participants, combined with one another, with some surviving, some dying out and some continuing in a form different from their origin (pp. 116-167). Policy windows close when the problem is either addressed, 
new problems take priority, the focusing event that opened the window disappears, or there is no readily available solution. Howlett's (1998) study of Canadian politics and Lieberman's (2002) research on the Chicago Public School System have, to some extent, tested and validated Kingdon's policy window approach.

However, while Kingdon's approach has been very influential and often cited, its main focus is upon the initiation and agenda setting phases of the policymaking process. In response, some scholars have called for the development of a more sequential evolutionary approach to the policymaking process. For example, Peter John (2003) argues that evolutionary theory may provide the best approach to conceptualizing, explaining and predicting outcomes of the policymaking process. He calls for empirical studies of policy theories that will capture the causal process from policy initiation to outcomes (p. 494-495). Similarly, Birkland (1997) calls for an approach to the policymaking process that "synthesizes existing theory... [and] transcends compartmentalization of the stages" (p. 5) and he suggests that rather than viewing the process as one with neatly defined stages, a better alternative is seeing the process as one with "categories of activities," (p. 5).

Overall, the prior literature fails to offer an empirically validated model of policymaking as a sequential and interrelated process with associated outcomes. The fundamental nature of the stages heuristic process has contributed to a fragmented approach to the study of policymaking with scholars focusing largely upon individual stages and neglecting the overall process and outcomes. Theories developed to explain a specific policy domain or long term policy trends, on the other hand, miss the more complete and interrelated policymaking process by centering their explanation upon the initial stages of policymaking. Finally, previous studies calling for a sequential or evolutionary process do not adequately address the interrelations among the stages, events and functions within the policymaking process. Clearly, a necessary next step in advancing the policymaking literature is to return to the empirically concrete and identify a sequential process and determine what propels the process from one stage to the next leading to particular outcomes. This paper responds to this need by providing a detailed case study of a policy window and the subsequent policymaking process and outcomes that emerged in Florida following the death of Martin Lee Anderson in a juvenile boot camp.

\section{The Current Study}

This paper's purpose is to develop and test a model that describes the processes and actors involved in policymaking. The policymaking model proposed in this paper is based upon different stages of policymaking that have been identified in prior studies. However, this model incorporates all stages, while many of the earlier studies limited their focus to only one or two components of the model. Although the components of the model are drawn from previous studies, it is unique in that it identifies the stages of the policymaking process in a sequential and interrelated manner. Additionally, the study determines how each stage in the policy process influences the next stage and identifies the major factors and actors that ultimately shape final policy outcomes. Figure 1 demonstrates the model.

\begin{tabular}{|c|c|c|c|c|}
\hline Phase I & Phase II & Phase III & Phase IV & Phase V \\
\hline $\begin{array}{l}\text { Triggering } \\
\text { Event }\end{array}$ & $\begin{array}{l}\text { Policy } \\
\text { Window }\end{array}$ & $\begin{array}{l}\text { Policy } \\
\text { Agenda }\end{array}$ & $\begin{array}{l}\text { Decision- } \\
\text { Making }\end{array}$ & $\rightarrow \quad \begin{array}{c}\text { Resulting Policy \& } \\
\text { Outcomes }\end{array}$ \\
\hline $\begin{array}{c}\text { Social / } \\
\text { Natural } \\
\text { Event }\end{array}$ & $\begin{array}{l}\text { Focus on a } \\
\text { particular } \\
\text { policy area }\end{array}$ & $\begin{array}{l}\text { Problem/ } \\
\text { Solutions }\end{array}$ & $\begin{array}{l}\text { Institutional } \\
\text { Procedures }\end{array}$ & $\begin{array}{c}\text { New/Revised Policy } \\
\text { Outcomes }\end{array}$ \\
\hline
\end{tabular}

Figure 1. Sequential model of policymaking

The proposed model of policymaking includes five main phases: 1) a social or natural event illuminates a social problem; 2) a policy window creates opportunity for policy issue(s) to be placed on the agenda; 3 ) the social problem is defined and solutions are proposed;4) decisions are made by policy-makers; and 5) policy is modified or created resulting in expected or unintended outcomes. The resulting policy outcomes are influenced by several groups throughout the process and these outcomes range in the level of reform from maintaining the status quo, to minor modifications in existing policy, creation of new policy, to organizational change in governmental services representing significant reform. Employing the model to structure our case study, we address the following research questions related to the processes and actors who shaped and influenced the policymaking processes and outcomes. 
1. What identifiable phases characterize the policymaking process?

2. What aspects of this process and actors influence policy outcomes?

3. How does the policymaking process result in expected and unexpected outcomes?

\section{Methods}

To describe and test our model, we conduct a case study of the Martin Lee Anderson Act in Florida. The case study provides an opportunity to explore policymaking as a process that evolves from agenda setting, policy negotiations, and outcomes. The case study covers the period beginning January, 2006 with the death of Martin Lee Anderson. It continues through the Florida legislative session ending in June, 2006 and includes the initial policy implementation phase six months following the enactment of the Martin Lee Anderson Act.

Case studies are generally employed in the social sciences to provide exploratory analysis of complex phenomena about which little is known. This study provides an extensive narrative that summarizes events of interest from a sequential perspective thereby allowing the examination of relationships among and between different stages, actors and outcomes. Case study methods are often employed after a phenomenon has occurred that allegedly produced change (Nachmias \& Nachmias, 1996). In conducting the case study, we employ data from multiple sources and utilize different data collection techniques. Specific sources of data include news/media articles, interviews with key actors in the policymaking process, observations of legislative committee meetings, and content analysis of such legislative documents as agendas, draft bills, budgets, and voting records.

Data from news articles include weekly counts of articles in two major Florida newspapers, and a review of 145 online news articles of the event. News articles were compiled from online sources within the state of Florida and national news organizations such as CNN, MSNBC, and USA Today. The review of these articles provided a timeline of events, identified actors in the policymaking process, helped document actors' reactions and preferences regarding solutions to the policy problem being addressed, and helped define actors' policy positions based on the level of policy change they supported. Through the review of legislative documents, we were able to track the development of legislation about the case. Document analyses included committee agendas, multiple drafts of the bill (eventually named the Martin Lee Anderson Act), appropriations bill, and conferencing documents between the Florida House of Representatives and Florida Senate. Legislative committee agendas were used to compare the number of committee meetings involving boot camps with the number of other legislative issues addressed during committee meetings in the House and Senate. The legislative agendas were also reviewed to determine which actors were directly involved, and how often they spoke with policy-makers during the process.

During the 2006 Florida legislative session, we observed four committee hearings of the House Criminal Justice Appropriations Committee. This committee was the lead committee in the Florida legislature investigating the Martin Lee Anderson case and held the most meetings regarding the incident. The four selected committee hearings involved testimony from the Florida Sheriffs Association, juvenile justice providers, legal representation of the deceased youth, Department of Juvenile Justice (DJJ) staff, research experts, and medical examiners.

Finally, in-depth interviews with four legislative staff and two legislators from both the House of Representatives and the Senate were conducted. Staff members are used as key informants concerning questions of general policymaking and specifics about the case under study. The interviews were semi-structured, allowing respondents to speak freely regarding their interpretation of events and lasted up to 90 minutes. Interview questions focused upon key events, actors and particular factors that influenced decision-making and policy outcomes regarding the Martin Lee Anderson Act.

\section{Findings}

The death of Martin Lee Anderson brought attention to several problems within Florida's juvenile justice system. First, the effectiveness of boot camps as a method for treating delinquency was questioned and debated. Second and beyond boot camps, the general standard of care for youth in state custody was questioned. Third, and very importantly, the independence of a state agency was questioned as policy-makers considered developing external governing and accountability systems for the state's DJJ.

Our findings documented that juvenile justice policy ranks low on the policy agenda of the legislative committees and membership on juvenile justice committees is often not sought by legislators. However, events such as the death of a child in state custody can place otherwise ignored juvenile justice policy issues at the very top of the political agenda. In Florida, the death of Martin Lee Anderson while in a juvenile boot camp triggered the actions of the Governor, legislators, agency administrators, special interest groups, child advocates, the media, and academic experts. These distinct groups typically have individual agendas and their particular roles in the 
policymaking process can be defined and studied. Understanding the major components of the process by which policy is created can reveal the sequential processes involved in policymaking. Using the major components of the policy process model identified earlier, the following sections describe the salient events, namely, the formation of the policy window, actors and their involvement in the process, proposed solutions, and immediate policy outcomes.

\subsection{Phase I - Triggering Event}

On January 6, 2006 fourteen-year-old Martin Lee Anderson died at a Florida Juvenile Boot Camp. The incident received immediate and sustained national and international media attention that helped generate a shockwave that rippled through Florida's political system during the 2006 Florida legislative session. Although the event was sudden, it may have been predictable and therefore preventable. As Kingdon asserts, most triggering events are precipitated by recognizable conditions that contribute to a tragedy which ultimately opens a policy window (2003, p. 169).

Indeed, prior to the death of Martin Lee Anderson several warning signs arose within Florida's DJJ system and its boot camps. From 2001 to 2005, four youth died while in custody of the Department and another mentally challenged youth was sexually assaulted by a sex offender while unsupervised (Abrams, 2005). In addition, use of force reports from the state's boot camps had been increasing over the preceding three years, reaching 180 incidents being reported by youth in the camps to the DJJ's central office (Miller, 2006). In summary, the media and public attention caused by the death of Martin Lee Anderson opened a policy window that noticeably placed juvenile justice policy on the state's legislative agenda.

\subsection{Phase II - The Policy Window}

Following Martin Lee Anderson's death, the initial reactions of DJJ, the Florida Department of Law Enforcement (FDLE), and the local county Sheriff who operated the boot camp were tentative and guarded as reflected in several statements each made that generally downplayed the tragedy. Within days, however, questions surfaced regarding the treatment of Anderson. Although ten days later the initial autopsy stated the official cause of death as a result of complications arising from Sickle Cell Trait, allegations of the youth being beaten by guards emerged. Members of the media learned that the altercation between Anderson and boot camp drill instructors was captured on video. As allegations that the death of Anderson occurred at the hands of boot camp drill instructors became known, the Miami Herald and CNN sued the state of Florida to release the video of the confrontation between the drill instructors and Anderson.

Ultimately, through the efforts of two prominent Florida legislators and media organizations the incident was brought to the public forefront. After watching the video just prior to its release to the general public, the two legislators stated they were concerned the boy may have been beaten to death and publicly criticized the use of force in the boot camp. On February 17, the video was released to the media and general public. Short segments of the video were shown on television and other media outlets throughout the country and the entire video could be viewed via the internet on the Miami Herald's website. The public was shocked by the images of a 14 year old boy being pushed, grabbed, kneed, and manhandled by several drill instructors who towered over the boy. Several times throughout the video the young Anderson appeared limp and unresponsive as the drill instructors continued their physical tactics. During the incident, a nurse employed by the boot camp walked in and out of the scene, but didn't stop or interfere with the drill instructors' physical actions.

These images instilled in the general public a sense of shock, outrage and injustice. With the release of the video and the public's response to the incident, a social mandate to correct the injustice was established, and a policy window was opened. As confirmed in the interviews, after having seen the video and its release to the general public, the legislature "couldn't [just] do nothing."

As various investigations were pursued, further events produced sustained media coverage of the incident, including a second autopsy, protests by university students and The National Association for the Advancement of Colored People (NAACP) at the state's capital in Tallahassee, and the resignation of a top state agency official for FDLE. Lawmakers and special interest groups helped keep attention focused on the incident throughout Florida's 2006 legislative session. These actors and their actions helped not only to open a policy window, but also to keep it open thereby expanding the policy domain by linking the effectiveness of juvenile boot camps to the more general mistreatment of youth in juvenile confinement, lack of accountability in the state's juvenile justice system, and the need for broad policy change. Interviews with legislators and staff confirmed that the media's coverage helped initiate and justify policy changes and propel the passage of a new law in the legislature. Although most respondents stated that the media did not have a strong effect in shaping the final policy outcome, they all agreed that the media contributed to a social mandate for policy change. 
Using the search engines of two prominent Florida newspapers, the Miami Herald and St. Petersburg Times, we measured the amount of media coverage to determine when and to what extent the policy window remained open. Two search terms, "Martin Lee Anderson" and "Boot Camp" were used to calculate weekly counts of news articles. Since the amount of coverage was nearly the same and there was a large overlap between coverage amounts obtained by the two search terms, only the results of the "Boot Camp" search term are presented in Figure 2.

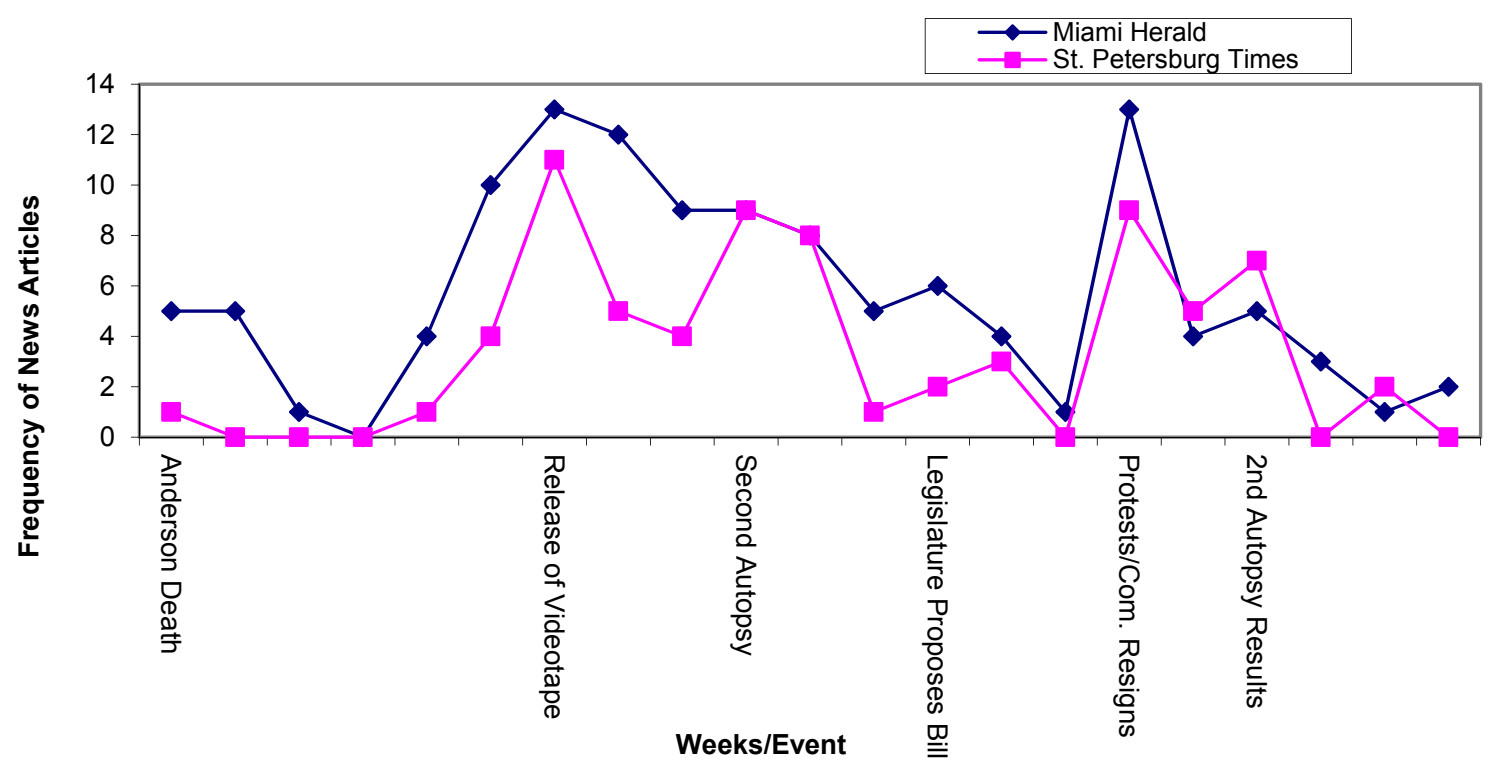

Figure 2. Media coverage of "Boot Camp"

As illustrated in Figure 2, the media persistently covered the incident between early January and late May. The release of the video created the largest amount of media coverage and was critical in opening the policy window. The video also helped create a social mandate, which moved government officials to respond. Although the level of media coverage fluctuates throughout Florida's 2006 legislative session, several key events such as the exhumation of the body for a second autopsy, and regular comments from state legislators kept the story prominent in the media. One legislator stated "... it's a moment for us as a state to stand up and say this is unacceptable, there are no excuses and let's make some drastic changes" (Leary \& VanSickle, 2006). Following the racial remarks of the state agency head of the FDLE which created more controversy, the public rallied, and together with the protests helped link the issue to civil rights. For instance, one legislator likened it to the Rodney King case, "only worse, because the kid died." (Leary \& VanSickle, 2006). Another legislator stated "would you ever have predicted that we, in America, in the state of Florida, would have to endure the same kinds of tragedies of racism, bigotry and hate." (Lush, 2006). Specifically, the addition of race into the already volatile issue caused the resignation of the Commissioner of FDLE, the state agency in charge of the investigation. The resignation, protests, and student sit-ins at the state's Capitol helped increase the prominence of symbolic politics, connecting the case to memories of the civil rights movement, all of which may have helped sustain the media coverage.

Overall, the initial tragedy of Martin Lee Anderson's death and the events that followed sustained the media and public's attention for an extended period of time. The youth's death and release of the video opened the policy window and the extended media coverage allowed the policy window to remain open, igniting concerns within the general public and thereby creating a social mandate which provided an opportunity for change in Florida's juvenile justice policy.

\subsection{Phase III - The Policy Agenda}

By creating a social mandate for change, the media and the general public helped place juvenile justice policy at the top of Florida's 2006 legislative agenda. To determine the prominence of the issue on the state's policy agenda, we determined the number of agenda items in four legislative committees. Most items on the legislative agenda only received one public hearing. In the case of juvenile justice policy only two issues (gender programming and boot camps) appeared on any of the four criminal justice committees' agendas more than once. However, the case 
of Martin Lee Anderson was the most prominent issue within the juvenile justice agenda items. It appeared five times on two separate House committee agendas, which was more than any other single issue and demonstrates its high priority on the state's policy agenda.

Using online news articles, all from recognizable state and national media sources, a total of 110 actor positions were coded for various actors. We used a scale ranging from 1 (maintaining the status quo) to 5 (maximum change) to code the actor preferences of six policy solutions. Initially, some actor groups argued that the incident was simply a rare anomaly and that no change to existing policy was needed. This position reflecting the status quo is coded as (1). Another proposed solution included minimum changes to regulations in the boot camps and was coded as minimal change (2). A third solution promoted the creation of a new type of program (STAR academies) to replace boot camps. Most actors promoting this solution also emphasized the need for extensive regulations bringing uniform standards of care in all juvenile justice programs. Although conceptually distinct, these two solutions became one in practice as the majority of actors promoted both solutions as one. We coded the actor statements defending either solution or both as moderate change (3). Some actors argued that boot camps were not effective and they should be closed. This position was defined as a significant change in policy and coded as (4). Finally, experts and some policy-makers argued that the problem was larger than that of boot camps and regulations, and related to a lack of accountability and oversight throughout the state's entire juvenile justice system. They proposed major organizational change that included an external and independent accountability system to oversee the state's DJJ system. This position was coded as maximum change (5).

Figure 3 provides the results of 70 coded public statements in the media by the various actor groups. The value indicates the mean level of policy change advocated by each actor group.

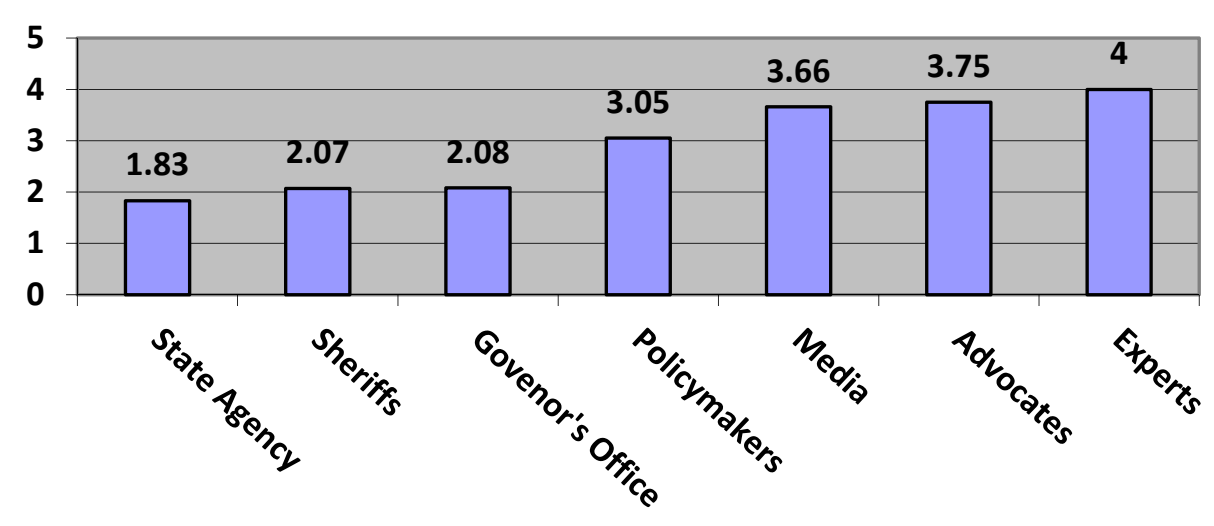

Figure 3. Level of policy change supported by actor group mean score

As Figure 3 reveals, experts, advocates and the media sought significant changes, while juvenile justice agency personnel and the Sheriffs' departments more often voiced minimal to moderate change. In many ways this might be expected, as when under public criticism, government agencies often react with survival instincts. Large government bureaucracies often resist change and prefer to maintain the status quo. On the other hand, experts may be more objective and seek the most effective solution beyond any bureaucratic survival tendencies or maintaining the status quo. Interview respondents felt that the position of the Governor's office did not influence the policy-makers decisions; however, the Governor's office served as a moderator helping reach a compromise among different policy solutions.

Interviews also confirmed that experts, policy-makers and the media were the more influential actor groups throughout the process. However, two respondents stated that agency personnel were very influential on the final policy outcome toward the end of the decision-making process. The actor involvement summarized in Figure 3 is generally in line with these perceptions (especially the Governor's position, which reflects a compromise point between minimal and maximum change, eventually leading to the outcome that was realized).

Policy positions of child advocacy groups and civil rights organizations were not as frequently cited in the media with respect to their positions. Civil rights organizations and student protests often called for "justice" in the case of Martin Lee Anderson, but usually did not offer policy solutions to achieve their call for "justice." Most of the 
interviewees stated they did not believe the civil rights organizations had a significant impact on proposed policy, but that they strengthened the social mandate and helped increase and maintain the media's and public's attention. During the 2006 Florida legislative session, while policy-makers were addressing the issues associated with Martin Lee Anderson's death, civil rights organizations and other public groups organized protests, rallies and sit-ins, which helped keep the issue at the forefront of the political agenda.

\subsection{Phase IV - Decision Making}

While various actors continued to communicate their preferences to the media, many groups directly participated in the policymaking process by taking part in legislative committee hearings. During the House committee hearings devoted to the issue of boot camps and the death of a youth in custody, several different actors testified before House committees. Actors involved in House committee testimony included juvenile justice agency personnel, representatives of local sheriff's departments, lobbyists from juvenile justice providers, medical examiners and researchers. Overall, 15 testimonies from DJJ personnel took place across five House committee hearings. This was compared to a total of nine testimonies from local sheriff's departments at two separate meetings, and lobbyists for juvenile providers and academic researchers at three separate hearings. Observations of committee hearings and a review of supporting documentation indicated that each of the various actor groups defined the problem differently and provided very different policy solutions.

DJJ agency personnel, testifying most frequently in the committee meetings, appeared to be eager to carryout decisions made by the policy-makers. During our interviews, we learned that the agency vigorously pled their case in the Senate to keep the existing structure of the agency relatively unchanged with less concern over the elimination of boot camps.

A content analysis of multiple bill drafts shows the clear influence of experts and agency personnel on the policymaking process. The bill emphasized the need for a new accountability system, an idea promoted by research experts. In the Bill Staff Analysis, references were made to expert testimony regarding the need for external oversight and accountability of the agency. The impact of other actors, most notably the sheriffs, can also be seen in the bill and staff analysis paper, where the concerns of the sheriffs are addressed. Some of these influences, particularly the influence of experts, were repeatedly stated by legislative staff during interviews.

While the text of the bill created an independent Juvenile Justice Accountability Commission to conduct quality assurance and program evaluation, this provision was replaced in joint conference by an internal DJJ Office of Program Accountability. The creation of a new commission may be defined as maximum change because it brings a significant organizational change and a diversion of funds. However, without the changes, it was a moderate policy change where boot camps were renamed with revised regulations. Although the proposed maximum change regarding an external accountability system to create oversight of the entire juvenile justice agency was in the bill and it was not opposed by the Governor's office, the department agreed to develop their own internal office of program accountability. Eventually, the negotiations that occurred during Senate and House conferencing reduced the significance of the policy modification from "maximum" change to "moderate" change.

After the public hearings in the House were complete and near the end of the legislative session, a "black box" of politics emerged during the conferencing between the House and Senate. Based upon interviews and legislative conferencing documents, it can be concluded that juvenile justice agency personnel successfully lobbied to drop the bill language regarding an external oversight committee for the agency and that the Florida Legislature instead agreed to allow DJJ to develop their own internal office of program accountability. The final bill implies a moderate change, however when assessed in relation to the policymaking process as a whole, the impact of the bill was still far reaching.

\subsection{Phase V - Resulting Policy and Outcomes}

The Martin Lee Anderson Act was first filed on March 31, 2006. It was approved after three amendments in the House on April 6, 2006. The bill was then approved in the Senate who requested the House to concur in conference committee. The conference committee amendment was filed on May 3, and the bill was approved as amended in conference committee in the House on May 5 (116 Yeas and 0 Nays) and in the Senate on May 5, 2006 (39 Yeas, 0 Nays). Ultimately, the resulting policy was approved by Florida's Governor on May 31, 2006.

In the end, the bill replaced boot camps with Sheriff's Training and Respect (STAR) Academies. It also required DJJ to adopt uniform rules on the use of force and physical constraints as well as Protective Action Response (PAR) training for employees prior to working with youth. These new policies reflected a more "hands-off" approach to behavior management within juvenile residential programs. Legislative staff and some legislators underlined the importance of these changes by stating that, all these changes bring regulations which will change the statewide 
policy regarding the treatment of youth in all of Florida's juvenile justice programs. According to some of the respondents, this was an important first step in changing the organizational culture of an agency that lacked uniform policies and standards in many areas.

Table 1 provides summary findings of all proposed solutions, actors' positions, resulting policy change and immediate results.

Table 1. Proposed solutions and outcomes

\begin{tabular}{|c|c|c|c|}
\hline Proposed Solution & Actors' Position & Resulting Policy Change & Outcomes \\
\hline Status Quo & $\begin{array}{l}\text { Original position of DJJ, Sheriffs } \\
\text { and Governor }\end{array}$ & $\begin{array}{l}\text { Not viable (media attention } \\
\text { and social mandate) }\end{array}$ & Status quo not maintained \\
\hline $\begin{array}{l}\text { Create STAR } \\
\text { Academies }\end{array}$ & All parties accepted this option & MLA Act & $\begin{array}{l}\text { Positive reaction to STAR } \\
\text { Academies }\end{array}$ \\
\hline $\begin{array}{l}\text { Uniform Standards } \\
\text { of Care }\end{array}$ & All parties accepted this option & $\begin{array}{l}\text { Protective Action Response } \\
\text { policy (PAR) }\end{array}$ & $\begin{array}{l}\text { DJJ promulgates rules on } \\
\text { uniform standards of care }\end{array}$ \\
\hline Close Boot Camps & $\begin{array}{l}\text { Not politically viable due to } \\
\text { Governor's Office and Sheriffs' } \\
\text { Association }\end{array}$ & No Mandate & $\begin{array}{l}5 \text { of } 6 \text { boot camps closed } \\
\text { independently }\end{array}$ \\
\hline $\begin{array}{l}\text { External } \\
\text { Accountability }\end{array}$ & $\begin{array}{l}\text { Accepted by most actors } \\
\text { DJJ lobbied to maintain authority }\end{array}$ & $\begin{array}{l}\text { DJJ agrees to create internal } \\
\text { office of accountability }\end{array}$ & $\begin{array}{l}\text { Internal reorganization of } \\
\text { DJJ }\end{array}$ \\
\hline
\end{tabular}

Table 1 lists the five seriously considered policy solutions proposed by various actors. The first option was maintaining the status quo; within this was the original position of DJJ, sheriffs and the Governor's office. However, this option was quickly eliminated based upon persistent media coverage and civil protests that fueled public concern and created a social mandate. The second option provided minimal changes to boot camps and was not realized for similar reasons. The third option included replacing boot camps with STAR academies and creating uniform standards of care throughout the system. Although appearing later than some of the other policy options, most parties accepted this option as a compromise and eventually the Martin Lee Anderson Act unanimously passed in the legislature with this policy change in place.

A fourth solution to close boot camps in Florida was found not to be politically viable because of opposition by the Governor's office and the sheriffs' departments. Finally, a more significant solution that involved reorganization of DJJ by creating an independent and external commission was considered. The commission was to serve as an external oversight and accountability office with direct responsibility for the Department's research and quality assurance functions thereby removing these functions from the Department. With the exception of DJJ, all parties agreed to the solution; however, efforts by DJJ in the Senate to maintain internal control resulted in this being removed from the bill. Although research experts and some legislators strongly supported the option for external accountability and oversight of DJJ's research and quality assurance functions, a possible reason for its elimination is that advocacy was not strong enough and failed to trigger public interest. Notwithstanding this, an indirect impact of these discussions made DJJ revise their organizational philosophy and come up with a proposal to create a new internal accountability office within the agency. In fact, interviews helped clarify that some legislators had a long standing discontent with the agency's culture and saw this bill as an opportunity to modify that culture by reorganizing the agency.

Although the Martin Lee Anderson Act did not directly close boot camps or reorganize the state's juvenile justice agency, the policy discussions led sheriffs to close all but one boot camp on their own and DJJ agreed to an internal agency reorganization by creating an office of program accountability within the Department. Overall, the triggering event of Martin Lee Anderson's death resulted in a policy change that can be categorized as moderate.

\section{Summary and Conclusion}

In this paper, we have proposed and applied a sequential model of policymaking that was largely supported by the data from our case study. In this concluding section we revisit our model of policymaking based upon our case study findings. We also discuss the applicability of the proposed model to other areas of policymaking. 
The sequential model of policymaking developed in this paper was used to explain the creation of a new policy. The following refinements to the model provide a more detailed depiction of the process, including different actor groups and their influence on policymaking. Figure 4 presents a refined model of policymaking.

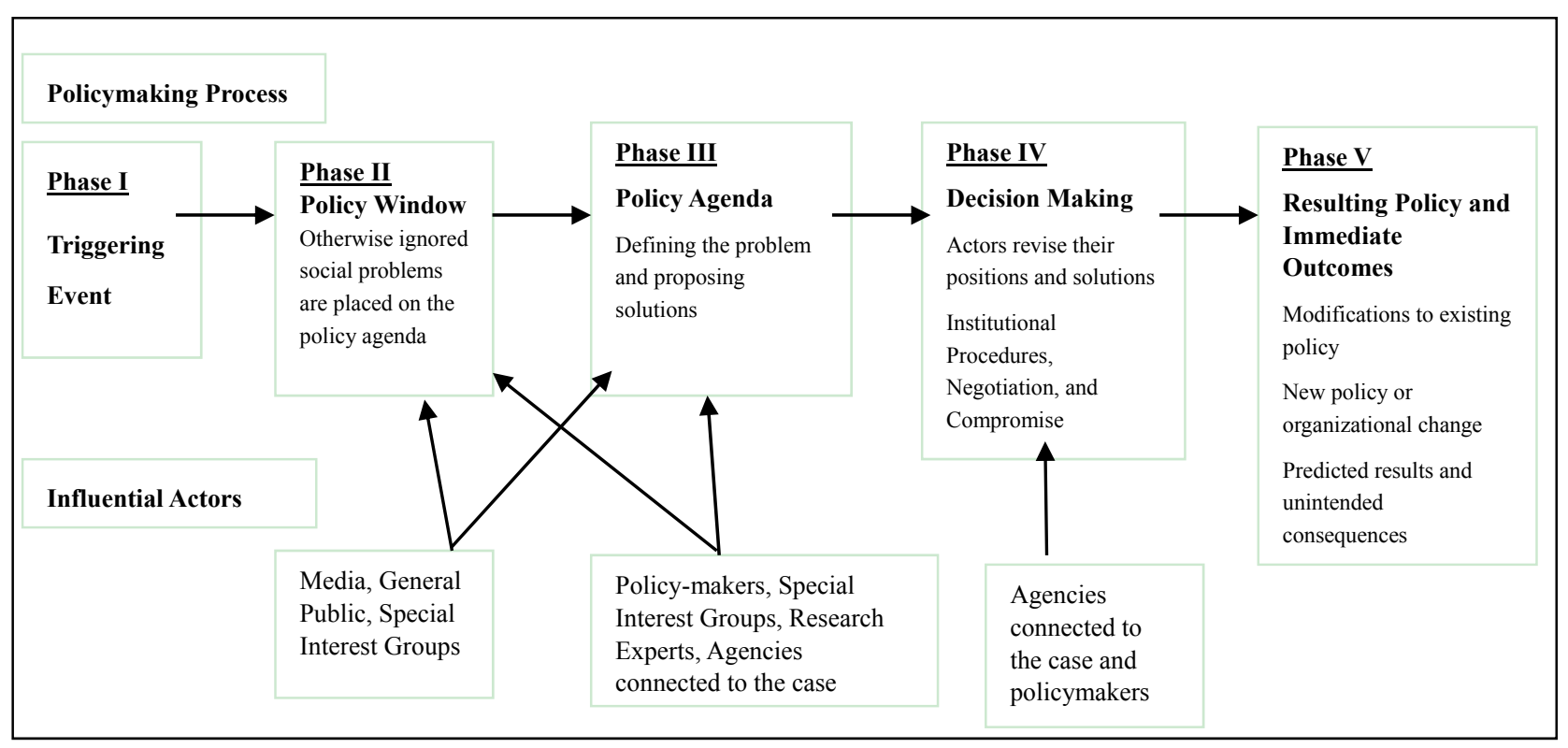

Figure 4. Level of policy change supported by actor group mean score

When applied to our case study of the death of Martin Lee Anderson in a Florida boot camp, the model specifies the following: First, the components of the policy process are sequential. The case evidence presented here demonstrates that these components represent stages in the process that ultimately shape and influence policy outcomes. Although not all policy efforts are initiated as a result of a social or natural tragedy that receives excessive media coverage, the stages of policymaking process likely remain the same. In other words, more normative policymaking may start with an initiative from legislators or other groups, (i.e., triggering event) and continue with the stages described in the proposed sequential model. Our interviewees stated that the stages of the policymaking process remain relatively unchanged regardless of whether a tragedy is involved or not. Therefore, we believe the stages of policy process identified in our model are applicable to policymaking in general. In addition, the outcome of each stage cumulatively influences the activities and outcomes of the next stage. Throughout the policymaking process, actors influence the policy agenda and outcomes by defining the problem being addressed and providing solutions. As the process evolves, proposed solutions are negotiated and modified resulting in an interrelated and cumulative outcome.

Although our findings indicate that several actor groups were involved in the policymaking process, many of these actor groups' influence was limited to the middle stages of the process when the policy agenda was being developed and solutions were being considered. Initially the actor groups were limited to the media and key policy-makers which helped to create a social mandate for change through images of injustice. During the middle stages of the process several special interest groups, research experts, and agency personnel contributed to defining the problem and proposing solutions. However, toward the end of the process, as policy-makers made key decisions, influence was limited to select groups who would be impacted most by the proposed policy changes, namely, sheriffs and DJJ personnel.

The refined model helps to answer our three research questions. The first question was what identifiable phases characterize the policymaking process? The case study findings confirm that the process can be summarized into the five stages of our proposed model. That is, following a triggering event, a policy window may open. This window of opportunity can lead to otherwise ignored social issues being placed on the policy agenda where the problem is defined and various solutions are proposed. Once different solutions are proposed, new policy is created within the decision-making structures of the policymaking body. The final stage is the resulting policy and immediate outcome stage which involves the revision of existing policy, creation of new policy, diversion of funds or organizational change of government entities. During these stages, different actors play different roles in 
influencing the final policy outcome. Ultimately, the model is parsimonious enough to be applied to like cases and it is broad enough to capture the complexities of numerous other policymaking events and areas.

The second research question concerns what aspects of this process and actor groups influence policy outcomes? Our findings indicate that the policymaking process that is triggered by, for example, a tragic event takes on a life of its own, and is influenced by numerous groups at different phases in the process. Actors and their solutions move throughout what can be characterized as a dynamic process of policymaking. As solutions are proposed (such as the closing of boot camps) by one actor group, other actor groups may propose alternative solutions (such as the modification of the boot camp treatment model). This represents an approach where all stages are interconnected and where they develop in a dynamic and politicized fashion. Accordingly, the model proposed here not only moves beyond a static schema of the stages heuristic approach (Lasswell, 1951; De Leon, 1999) but also incorporates some arguments of such approaches as the advocacy coalition framework (Sabatier \& Jenkins-Smith, 1993).

Our findings document that the media was important in creating and maintaining a social mandate for change. The media created pressure on legislators to take action by sustaining public awareness of issues regarding juveniles in confinement. In this case, the amount and persistence of media coverage made it imperative for lawmakers to create and support a bill that would satisfy their constituencies. The legislators knew they had to answer to their constituents as the media continued to cover the issue. Calls for justice from civil rights organizations and child advocacy groups helped reinforce this social mandate, but did not directly influence the policy outcome according to the legislative specialists and legislators. However, in other settings these groups may assume a more active role in determining the policy outcome. In addition, different policy-makers were involved at the beginning and the end of the process and had varying degrees of influence on the policy outcome. Agencies highlighted by the incident reverted to a self-preservation strategy, revising their philosophy when necessary to ensure their survival, which reduced the magnitude of policy/organizational change. By allowing the investigations to proceed and actors to push their agendas, the Governor's office performed a moderating role, ultimately agreeing to the final compromises reached by the policy-makers. Finally, experts helped define the problem's scope as larger than just an issue of boot camp personnel or program effectiveness, and provided objective evidence to empower policy-makers who otherwise might not have gained support for their proposals. Experts played an important role by actively getting involved in the entire process and by framing the problem and the solutions for the media, public and policy-makers. In addition, expert opinions were often used by policymakers and advocates to legitimate the case for policy change. Thus, as this case demonstrates, experts can play a crucial role in agenda setting and in proposing policy solutions. Overall, we expect that these different actors will play similar or even more major roles in other cases of the policymaking process given increasing fiscal scarcity and associated demands for evidence-based policies.

The third research question concerns how the process resulted in expected and unexpected outcomes? The findings presented here suggests that, a better model of the policymaking process can be obtained by connecting the different stages into an evolutionary narrative, as suggested by John (2003). While many well-developed theories of public policy start from the initiation phase (e.g., agenda setting, policy window) and construct stories of policymaking framed by these early stages (Kingdon, 2003; Baumgartner and Jones, 1993; Sabatier and Jenkins-Smith, 1993), our model incorporates shifting preferences of actors into more of a linear and cumulative process. Consequently, it is better suited to explain policy outcomes, both intended and unintended, that are not completely determined by the requisites of initiation or agenda setting, but also by shifting preferences and changes in agendas throughout the policymaking process. For example, given the prior incidents involving the treatment of youth and the social mandate created by the media and public, one could have expected results to include a significant organizational change. However, critical decision making inside the "black box" of politics, influenced by negotiation and compromise, tempered these initial reactions and ultimately led to only a moderate change in policy.

After the 2006 Florida Legislative session, the family of Martin Lee Anderson filed a lawsuit with DJJ and the Bay County Sheriff's office seeking more than $\$ 40$ million. As part of the 2007 Florida legislative agenda, policy-makers sought to financially compensate the family by passing a bill that would provide them with five million dollars. Florida's newly elected Governor signed the compensation bill on May 23, 2007. The Bay County Sheriff's office settled with the Anderson family for $\$ 2.4$ million. Seven guards and the nurse employed at the camp faced charges of aggravated manslaughter, but were all acquitted.

Although we categorized the resulting policy as moderate change, expected and unintended results indicate the event may have influence beyond the immediate policy. The discussion that occurred during the policymaking process brought to light several problems relating to the boot camp model, treatment of youth in custody, and 
accountability. Initially, five of the six local sheriffs' departments decided to close their juvenile boot camps rather than redesign their program models based upon the new STAR Academy requirements. After redesigning their program model to meet the STAR requirements, the sixth boot camp also closed, thereby eliminating boot camp models in Florida. The discussion regarding the treatment of youth in confinement may continue to influence how programs operate and how the state monitors the treatment of youth in its custody. In addition, the internal reorganization of DJJ will continue to influence the organization's culture, which may result in better accountability practices that ensure the safety of youth.

This paper examined the process of policymaking by articulating and applying a process model. The model introduces a series of linked stages and activities of the policymaking process. It incorporates actor involvement and the dynamic of changing preferences of actors throughout the policymaking process. It is difficult to capture the black box of politics in the policy process with conventional approaches and methods. However, this study demonstrates that in-depth interviews and participant observation can capture some of the salient political dynamics involved in policymaking. The in-depth interviews and the observation of the committee meetings allowed us to incorporate some of black box activities into our model and empirically assess their existence. The model is also capable of accounting for unintended outcomes of policymaking. The model of the policymaking process is a helpful conceptual tool in explaining and predicting changes, as well as accounting for intended and unintended outcomes of the process. As such, it can be applied to other policy cases and can be subjected to further empirical testing and refinements, particularly related to the role of politics and informal agreements.

Within the disciplines of criminology and sociology there is a move toward an increased "public policymaking role." "Public sociology," as proposed by Burawoy (2005), seeks to contribute to civil society in an effort to make the world better. Similarly, in criminology, the American Society of Criminology began publishing the journal Criminology and Public Policy in 2001. The journal is aimed at systematically connecting criminological scholarship to timely matters of public policy related to reducing the pain and suffering of crime. As part of this overall effort, both the American Society of Criminology and the American Sociological Association are individually working on institutionalizing congressional briefings and other federal organization relationships to advance evidence-based policy through the sharing of research. Clearly, if these efforts are to prove successful over the long course, academic communities must become more informed about the policymaking process and how they can best contribute to this process. To do so will require more evaluation strategies centered upon describing, explaining and predicting the policymaking process.

\section{References}

Abrams, D. E. (2005). Reforming juvenile delinquency treatment to enhance rehabilitation, personal accountability, and public safety. Oregon Law Review, 84(4), 1001-1092.

Anderson, J. (1975). Public policy-making. New York: Praeger.

Baumgartner, F. R., \& Jones, B. D. (1993). Agendas and instability in American politics. Chicago: University of Chicago Press.

Baumgartner, F. R., \& Jones, B. D. (2002). Policy dynamics. Chicago: University of Chicago Press.

Berry, F. S., \& Berry, W. (1990). State lottery adoptions and policy innovations: An event history analysis. American Political Science Review, 84, 395-415. http://dx.doi.org/10.2307/1963526

Birkland, T. A. (2004). The world changed today: Agenda setting and policy change in the wake of the September 11 terrorist attacks. The Review of Policy Research, 21, 179-200. http://dx.doi.org/10.1111/j.1541-1338.2004.00068.x

Birkland, T. A. (2005). An introduction to the policy process: Theories, concepts, and models of public policy (2nd ed.). Armonk: M.E. Sharpe.

Birkland, T. A. (2007). After disaster: Agenda setting, public policy, and focusing events. Washington, DC: Georgetown University Press.

Brewer, G. D., \& De Leon, P. (1983). The foundations of policy analysis. Monterey: Brooks/Cole.

Burawoy, M. (2005). 2009 American Sociological Association Presidential Address: "For Public Sociology". American Sociological Review, 70, 4-28. http://dx.doi.org/10.1177/000312240507000102

Burstein, P. (1991). Policy domains: Organization, culture, and policy outcomes. Annual Review of Sociology, 17, 327-350. http://dx.doi.org/10.1146/annurev.so.17.080191.001551 
Clark, B. R. (1956). Organizational adaptation and precarious values: A case study. American Sociological Review, 21(3), 327-336. http://dx.doi.org/10.2307/2089288

De Leon, P. (1999). The stages approach to the policy process: What has it done? Where is it going? In P. A. Sabatier (Ed.), Theories of the Policy Process (pp. 19-32). Boulder: Westview Press.

Downs, A. (1972). Up and down with ecology-The issue attention cycle. The Public Interest, 28, 38-50.

Emerson, R., Fretz, R., \& Shaw, L. (1995). Writing ethnographic fieldnotes. Chicago: University of Chicago Press. http://dx.doi.org/10.7208/chicago/9780226206851.001.0001

Howlett, M. (1998). Predictable and unpredictable policy windows: Institutional and exogenous correlates of Canadian federal agenda setting. Canadian Journal of Political Science, 31, 495-524. http://dx.doi.org/10.1017/S0008423900009100

Jenkins-Smith, H. C. \& Sabatier, P. A. (1994). Evaluating the advocacy coalition framework. Journal of Public Policy, 14, 98-130. http://dx.doi.org/10.1017/S0143814X00007431

John, P. (2003). Is there life after policy streams, advocacy, coalitions, and punctuations: Using evolutionary theory to explain policy change? The Policy Studies Journal, 31, 481-498. http://dx.doi.org/10.1111/1541-0072.00039

Jones, C. (1984). An introduction to the study of public policy (3rd ed.). Belmont: Wadsworth.

Kingdon, J. W. (2003). Agendas, alternatives, and public policies (2nd ed.). New York: Addison-Wesley Educational Publishers.

Lasswell, H. D. (1951). The policy orientation. In D. Learner, \& H. Lasswell (Eds.), The Policy Sciences: Recent Developments in Scope and Method. Stanford: Stanford University Press.

Leary A., \& Vansickle, A. (2006). Outrage builds over beating tape. St. Petersburg Times. Retrieved from http://www.sptimes.com/2006/02/15/State/Outrage_builds_over_b.shtml.

Lieberman, J. (2002). Three streams and four policy entrepreneurs converge: A policy window opens. Education and Urban Society, 34, 438-450. http://dx.doi.org/10.1177/00124502034004003

Lush, T. (2006). Body removed for second autopsy. St. Petersburg Times. Retrieved from http://www.sptimes.com/2006/03/10/news_pf/State/Body_removed_for_2nd_.shtml.

Miller, C. M. (2006). Boot camps inspections missed red flags. Miami Herald, 23, 5.

Ostrom, E. (1986). An agenda for the study of institutions. Public Choice, 48, 3-25. http://dx.doi.org/10.1007/BF00239556

Ostrom, E. (1990). Governing the commons. Cambridge: Cambridge University Press.

Ostrom, E. (1999). Institutional rational choice: An assessment of the institutional analysis and development framework. In P.A. Sabatier (Ed.), Theories of the Policy Process (pp. 21-64). Boulder: Westview Press.

Peters, G. B., \& Hogwood, B. W. (1985). In Search of the Issue Attention Cycle. The Journal of Politics, 47, 238-253. http://dx.doi.org/10.2307/2131074

Sabatier, P. A. (1999). Theories of the policy process. Boulder: Westview Press.

Sabatier, P. A., \& Jenkins-Smith, H. C. (1988). Special issue: Policy change and policy oriented learning: Exploring an advocacy coalition framework. Policy Sciences, 21, 123-278. http://dx.doi.org/10.1007/BF00136405

Sabatier, P. A., \& Jenkins-Smith, H. C. (1993). Policy change and learning: An advocacy coalition approach. Boulder: Westview Press.

\section{Copyrights}

Copyright for this article is retained by the author(s), with first publication rights granted to the journal.

This is an open-access article distributed under the terms and conditions of the Creative Commons Attribution license (http://creativecommons.org/licenses/by/3.0/). 